\title{
Rhodococcus equi, primer reporte de un caso de enfermedad diseminada en el Perú
}

\author{
Rhodococcus equi, first case report of disseminated disease in Peru
}

Gino Patrón-Ordóñez ${ }^{1,2}$ y Jean Carlos Risco-Rebaza ${ }^{3}$

"Facultad de Medicina Humana "Manuel Huamán Guerrero". Universidad Ricardo Palma. Lima, Perú.

${ }^{2}$ Hospital Nacional Dos de Mayo-Sala de Medicina Julián Arce. Lima, Perú.

${ }^{3}$ Facultad de Medicina "San Fernando". Universidad Nacional Mayor de San Marcos. Lima, Perú.

Los autores señalan no tener conflictos de interés.

Autofinanciado.

Recibido: 20 de enero 2020 / Aceptado: 28 se septiembre de 2020

\section{Resumen}

Presentamos el caso de un paciente con infección por virus de inmunodeficiencia humana (VIH) con recuento de LTCD4+ 49 céls/ $\mathrm{mm}^{3}$, que consultó por un cuadro de siete meses de baja de peso, dolor abdominal, diarrea crónica y lesiones cutáneas gomosas. El mielocultivo y hemocultivos fueron positivos para Rhodococcus equi. Además, se observaron lesiones histológicas en piel e intestino compatibles con este agente como malacoplaquia, reacción granulomatosa y cuerpos de Michaelis-Gutmann. Se descartó compromiso pulmonar mediante tomografía de tórax. Recibió terapia antibacteriana combinada con claritromicina, imipenem y vancomicina. A pesar del tratamiento, el paciente evolucionó desfavorablemente y falleció.

Palabras clave: Rhodococcus equi; inmunosupresión; virus de inmunodeficiencia humana; infección oportunista.

\section{Introducción}

$R$ hodococcus equi es una bacteria grampositiva pleomórfica de relevancia clínica en medicina veterinaria, que ha sido descrita como causante de enfermedad pulmonar en caballos jóvenes. Puede ser transmitida al ser humano fundamentalmente por inhalación desde el suelo, por lo que es considerada una zoonosis. En humanos afecta sobre todo a pacientes inmunocomprometidos, principalmente con infección por $\mathrm{VIH}^{1,2}$. Ocasiona habitualmente una neumonía cavitada, semejante al compromiso pulmonar por otros agentes oportunistas como Mycobacterium tuberculosis, Histoplasma capsulatum, Nocardia sp, entre otros.

\begin{abstract}
We present the case of a patient with human immunodeficiency virus (HIV) with a LTCD4 + 49 cells $/ \mathrm{mm}^{3}$, who was admitted due to a seven-month period of weight loss, abdominal pain, chronic diarrhea and rubbery skin lesions. Myeloculture and blood cultures were positive for Rhodococcus equi. In addition, histological lesions in the skin and intestine compatible with this agent were observed, such as malacoplachy, granulomatous reaction and Michaelis-Gutmann bodies. Pulmonary involvement was ruled out by chest tomography. The patient received antibacterial therapy combined with clarithromycin, imipenem, and vancomycin. Despite the treatment, the patient evolved unfavorably and died.

Key words: Rhodococcus equi; immunosuppression; human inmunodeficiency virus; opportunistic infection.
\end{abstract}

Comunicamos el primer caso de una infección diseminada por $R$. equi en el Perú, con compromiso digestivo, cutáneo, diseminación hematógena e invasión medular en un paciente con infección por VIH.

\section{Caso clínico}

Varón de 20 años natural de Tarapoto, una localidad en la selva del Perú, donde se dedicaba a la agricultura y crianza de una yegua. Consultó por un cuadro de siete meses caracterizado por baja de peso, dolor cólico en mesogastrio y fosa iliaca derecha, vómitos y diarrea sin mucosidad ni sangre. En su ciudad de origen se le diagnosticó una tuber- 
culosis enteroperitoneal, basado en los hallazgos clínicos y tomográficos, sin confirmación bacteriológica, además de una infección por VIH. Inició terapia anti-retroviral (TAR) y anti-tuberculosa, sin embargo, al no presentar mejoría fue derivado a un hospital de referencia en Lima.

Se constató un paciente enflaquecido, con funciones vitales estables. En la piel presentaba lesiones gomosas en el mentón, brazo y muslo derechos de aproximadamente $1,5 \mathrm{~cm}$; no dolorosas, y que en su evolución drenaron una secreción seropurulenta (Figura 1). El abdomen se encontraba distendido, con movimientos peristálticos visibles, doloroso y resistente a la palpación en el cuadrante inferior derecho. El resto del examen físico no fue significativo.

Dentro de los exámenes de laboratorio al ingreso, destacó un hemograma con una hemoglobina $8,1 \mathrm{~g} / \mathrm{dl}$, leucocitos 5.370 céls $/ \mathrm{mm}^{3}$, neutrófilos 3.812 céls $/ \mathrm{mm}^{3}$. El perfil hepático mostró una albúmina sérica $2,7 \mathrm{~g} / \mathrm{dl}$, fosfatasa alcalina 242 U/1; GGT 257 U/1. Los niveles de bilirrubina y transaminasas fueron normales, así como la glicemia, urea y creatinina. Las pruebas de LDH y $\beta_{2}$-microglobulina fueron normales. La prueba serológica de ELISA para VIH fue reactiva, el recuento de LT CD4 fue 49 céls $/ \mathrm{mm}^{3}$ y la carga viral 29.300 copias/ $\mathrm{ml}$. Las tinciones de esputo, orina y heces, buscando bacilos ácido-alcohol resistentes, fueron negativas en tres muestras consecutivas. El examen parasitológico seriado de deposiciones no mostró quistes, huevos ni larvas de parásitos. Las serologías para hepatitis B, C, sífilis, HTLV I-II y citomegalovirus fueron negativas.

El mielograma fue informado como una médula ósea reactiva a un proceso inflamatorio-infeccioso, siendo las tinciones de Ziehl-Nielsen, auramina, PAS y plata metenamina negativas para micobacterias y hongos; mientras que el mielocultivo y hemocultivo fueron positivos para Rhodococcus equi.

La detección de R. equi en el mielocultivo y hemocultivo se realizó por métodos automatizados mediante el equipo BACTEC ${ }^{\mathrm{TM}}$ TX y luego por el BD PHOENIX ${ }^{\mathrm{TM}}$ 100. El mielocultivo se informó como positivo en un día, $18 \mathrm{~h}$ y el hemocultivo a los dos días, $7 \mathrm{~h}$ para $R$. equi. Las muestras se cultivaron en agar sangre a $35^{\circ}$ y se realizó la prueba de CAMP con especies de Listeria, donde se observó hemólisis sinérgica con Listeria ivanovii, reacción específica que se observa con $R$. equi (Figura 2). El antibiograma no fue realizado ya que en esa época (año 2017) el Clinical and Laboratory Standards Institute (CLSI) no había estandarizado el estudio de susceptibilidad a los antimicrobianos para este microorganismo.

La radiografía y tomografía computarizada (TC) multicorte de tórax fueron normales, mientras que la TC abdominal mostró una hepatoesplenomegalia, múltiples adenopatías retroperitoneales, ascitis leve y engrosamiento del íleon terminal, hallazgos sugerentes de una tuberculosis enteroperitoneal (Figura 3).
El estudio histopatológico de la biopsia de la lesión cutánea reveló una úlcera crónica que comprometía hasta el tejido celular subcutáneo, con una reacción crónica granulomatosa tuberculoide. Sin embargo, las tinciones de Ziehl-Nielsen, auramina, PAS y plata metenamina fueron negativas, lo mismo que los cultivos de tejidos en búsqueda de micobacterias y hongos.

Debido al cuadro de diarrea crónica se realizó una colonoscopia, observándose múltiples lesiones redondeadas en la mucosa, aproximadamente de 4 a $8 \mathrm{~mm}$, las cuales eran blandas y friables (Figura 4), y se extendían hasta el íleon terminal. La histología de estas lesiones reveló una malacoplaquia de colon e íleon, colitis crónica xantogranulomatosa y presencia de cuerpos de MichaelisGutmann (Figura 5).

Con los resultados del mielocultivo, hemocultivos y los hallazgos histológicos de la biopsia intestinal, se hizo

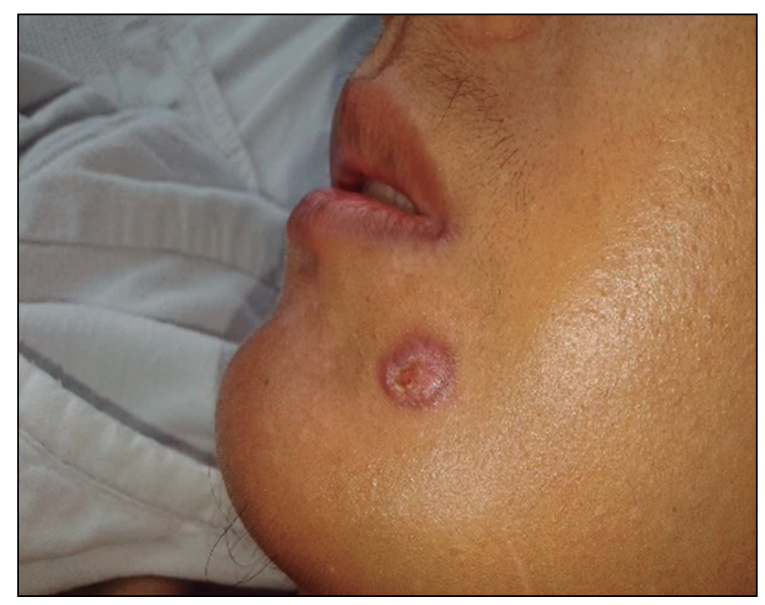

Figura 1. Lesión gomosa en la cara que en su evolución drenó una secreción seropurulenta. Se observaron similares lesiones en brazo y muslo derechos.

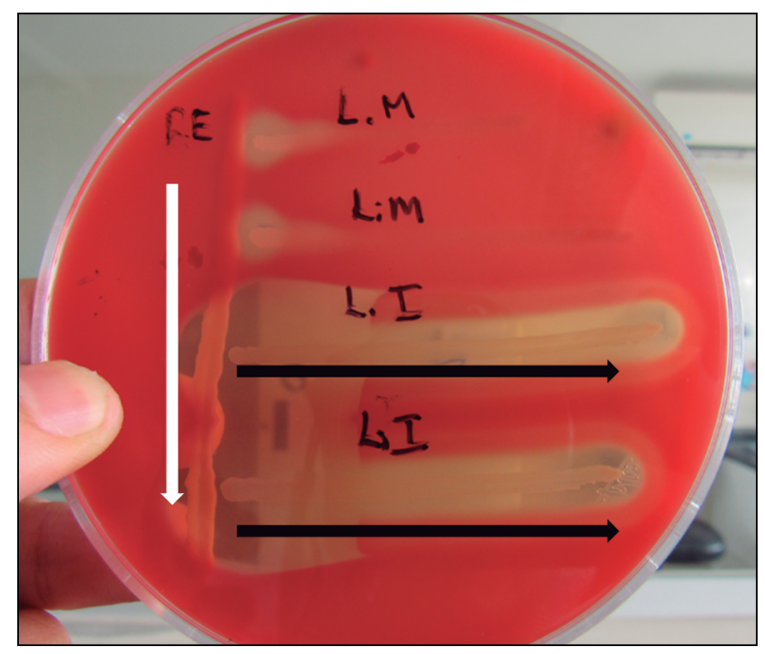

Figura 2. Test de CAMP. Cultivo en agar sangre donde se observa en forma vertical (flecha blanca) una coIonia de Rhodococcus equi (RE). En sentido horizontal fueron sembradas cepas de Listeria monocytogenes (LM) y Listeria ivanovii (LI), observándose mayor hemólisis en esta última (flechas negras). 
Figura 3. TC multicorte abdominal con contraste que mostró hepatoesplenomegalia, adenomegalias, ascitis y engrosamiento del íleon terminal, hallazgos sugerentes de una tuberculosis enteroperitoneal.
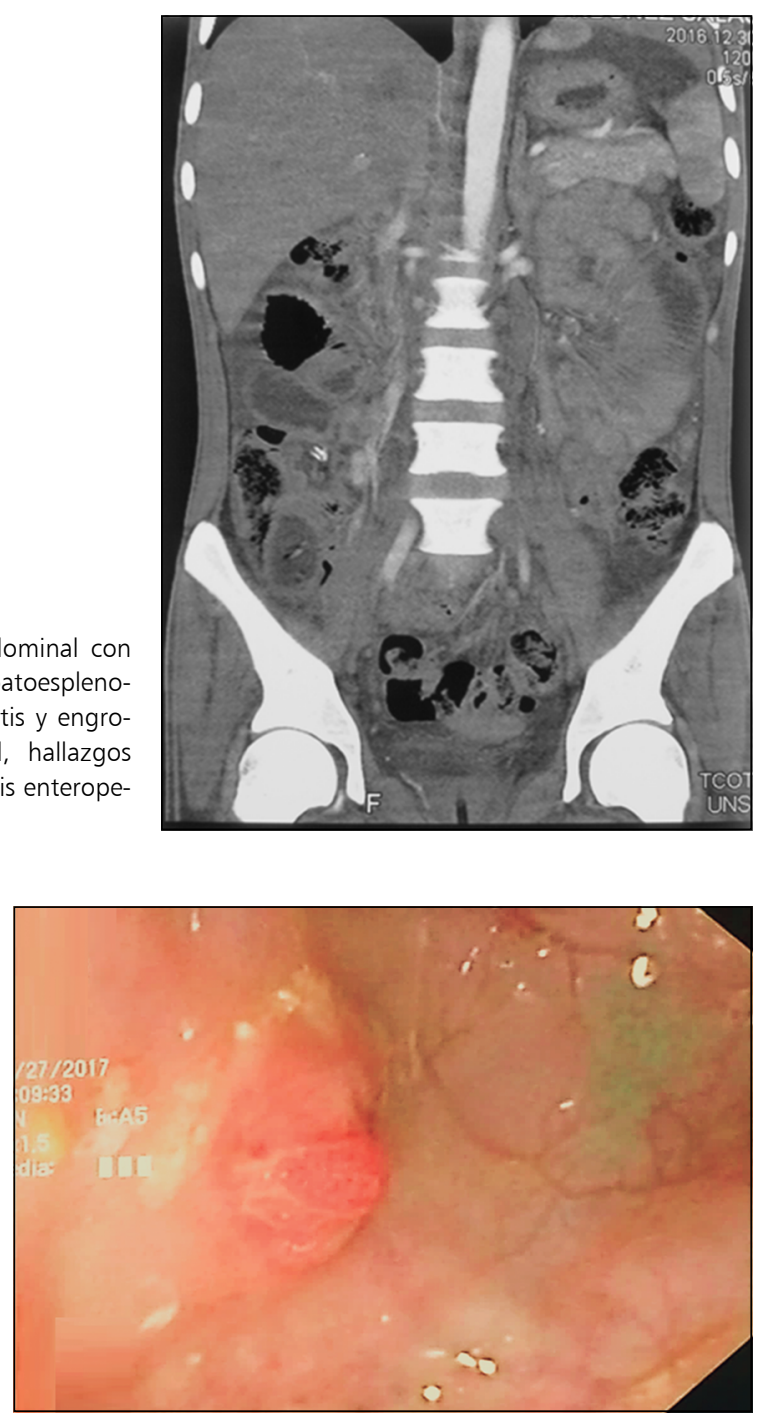

Figura 4. Colonoscopia en que se observa una de las múltiples lesiones elevadas que se encontraron en todo el intestino grueso y el íleon terminal.

Figura 5. Estudio histopatológico de una lesión de colon donde se observa una reacción granulomatosa con cuerpos de MichaelisGutmann (flecha), hallazgos compatibles con una malacoplaquia. el diagnóstico de una infección sistémica por $R$. equi, iniciándose tratamiento con imipenem, claritromicina y vancomicina. Pese a la terapia el paciente presentó una evolución tórpida, cursando con una hipotensión e hipoglicemia sin respuesta a hidrocortisona y finalmente falleció.

La necropsia tuvo como hallazgos una peritonitis generalizada con perforación de la pared colónica y una yeyuno-ileítis crónica hemorrágica, poliserositis, múltiples linfoadenomegalias y glándulas suprarrenales con cambios necrohemorrágicos, los cuales podrían haber explicado los episodios de hipotensión e hipoglicemia que se presentaron hacia el final de la enfermedad. El estudio histopatológico de las muestras obtenidas de yeyuno, íleon y colon volvieron a encontrar una malacoplaquia y presencia de cuerpos de Michaelis-Gutmann. El estudio de los pulmones solo mostró pequeñas atelectasias basales, sin encontrar algún compromiso parenquimatoso inflamatorio o cavitario.

\section{Discusión}

Rhodococcus equi es un coco-bacilo gram-positivo, conocido anteriormente como Corynebacterium equi. Fue aislado en 1923 por Magnusson en potrillos con neumonía piogranulomatosa y reportado en humanos por primera vez en 1967. Comparte características de otros géneros bacterianos como Nocardia sp. y Mycobacterium sp., como por ejemplo, una pared de ácidos micólicos, pudiendo presentar una reacción ácido-alcohol resistente ${ }^{1,2}$.

El caso clínico presentado tenía antecedente de ser agricultor y dedicarse a la crianza de una yegua. Está descrito que $R$. equi afecta principalmente a caballos jóvenes que excretan el microorganismo por sus heces, transmitiéndose a humanos principalmente por inhalación desde el suelo, aunque también ocurre por inoculación directa, ingesta y diseminación hematógena como vías de infección. Sin embargo, este antecedente epidemiológico se ha reportado solo en un tercio de los $\operatorname{casos}^{1,2}$.

El caso presentado corresponde a un paciente con infección por VIH en etapa avanzada con una infección sistémica por R. equi. El grupo de pacientes con LT CD4 menor a 100 céls $/ \mathrm{mm}^{3}$ es el que concentra los dos tercios de la infección descrita, y en los que la mortalidad puede llegar a $56 \%$. La letalidad disminuye a $8 \%$ en presencia de $\mathrm{TAR}^{3-6}$. Otras condiciones de inmunosupresión como el uso crónico de corticoesteroides, trasplante de órganos, linfoma o leucemia están presentes hasta en $90 \%$ de los casos de infección por $R$. equil ${ }^{1,2,4,7,8}$.

El compromiso pulmonar se encuentra en más de $80 \%$ de los casos reportados, causando una neumonía cavitaria de los lóbulos superiores de evolución subaguda, absceso pulmonar, efusión pleural, empiema y mediastinitis. 
También se ha descrito con menos frecuencia nódulos o abscesos cutáneos, compromiso musculo-esquelético como osteomielitis o artritis séptica, linfoadenomegalias generalizadas y abscesos cerebrales, hepáticos, esplénicos, renales, prostáticos, tiroideos, de psoas y pericarditis $^{9-12}$. Todas estas manifestaciones pueden confundirse con otras infecciones oportunistas causadas por micobacterias, hongos o neoplasias como linfomas, o bien presentarse en el contexto de un síndrome de reconstitución inmune ${ }^{13}$. Por esto, es necesario tener una alta sospecha clínica y descartar adecuadamente otras patologías, sobre todo en un país como Perú donde la tuberculosis tiene una alta prevalencia y ambos cuadros pueden ser indistinguibles ${ }^{2,14,15}$. En nuestro caso clínico, el compromiso principal fue digestivo y cutáneo, con diseminación hematógena e invasión medular, llamando la atención la ausencia de compromiso pulmonar, lo cual es una forma infrecuente de presentación y que se observa principalmente en personas inmunocompetentes ${ }^{3}$.

Rhodococcus equi se aisla fácilmente en muestras de sangre, tejido, secreciones y heces, ya que tiene un crecimiento rápido en medios de cultivo tradicionales como agar sangre, chocolate y caldo de tioglicolato ${ }^{6,9}$. En nuestro caso, el diagnóstico se hizo por aislamiento de $R$. equi en el mielocultivo y hemocultivo mediante métodos automatizados, además de su identificación bioquímica con la prueba de CAMP. Su aislamiento en mielocultivos es poco frecuente, reportándose la muestra de esputo como la de mayor rendimiento diagnóstico ${ }^{1,6}$.

En relación al hallazgo de malacoplaquia en las muestras de tejido intestinal en nuestro paciente, esta se describe como un proceso granulomatoso crónico de las mucosas, con presencia de infiltración de macrófagos y calcificaciones conocidas como cuerpos de MichaelisGutmann. Su presencia es consistente con $R$. equi pero no específica, ya que se pueden encontrar también en infecciones fúngicas, tuberculosas o bacterianas como Escherichia coli o Pasteurella multocida. Esta lesión producida por $R$. equi es determinada por factores de virulencia como el gen vapA, descrito en equinos con infección pulmonar grave por $R$. equi ${ }^{1,2}$. Las lesiones granulomatosas de la biopsia cutánea, si bien tampoco son patognomónicas de $R$. equi, también son descritas en esta infección.

En cuanto al tratamiento, $R$. equi ha mostrado susceptibilidad in vitro en estudios animales y humanos a macrólidos, rifampicina, aminoglucósidos, fluoroquinolonas, carbapenémicos y vancomicina, sugiriéndose esquemas en base a terapia combinada con dos o tres fármacos para evitar la resistencia bacteriana y que incluyan antibacterianos con actividad intracelular, como rifampicina o macrólidos. La duración recomendada es de al menos seis meses ${ }^{1,3,6}$ y hasta que el recuento de LT CD4 sea mayor de 200 céls $/ \mathrm{mm}^{3}$ para evitar las recaídas, que se dan sobre todo en los casos con compromiso extrapulmonar ${ }^{16,17}$. Hay que considerar los reportes de resistencia en equinos a macrólidos y rifampicina ${ }^{18}$, por lo que el tratamiento debería ser guiado según el antibiograma; sin embargo, el estudio de susceptibilidad recién está siendo estandarizado. La terapia elegida en nuestro caso fue con claritromicina, imipenem y vancomicina, a pesar de la cual el paciente evolucionó desfavorablemente y falleció. El estudio anatomopatológico sugirió que el compromiso suprarrenal podría haber sido el gatillante de esta tórpida evolución, cursando el paciente con hipotensión e hipoglicemia que no respondieron a hidrocortisona.

\section{Conclusiones}

La infección por $R$. equi debe estar considerada, junto con infecciones por micobacterias y micosis, dentro del diagnóstico diferencial de compromiso multiorgánico granulomatoso en pacientes inmunocomprometidos, asociado o no con infección pulmonar. Este el primer caso de infección diseminada por $R$. equi reportado en Perú y es de especial interés por las localizaciones infrecuentes como piel y médula ósea.

\section{Referencias bibliográficas}

1.- Yamshchikov A V, Schuetz A, Lyon G M. Rhodococcus equi infection. Lancet Infect Dis 2010; 10: 350-9. doi: 10.1016/S14733099(10)70068-2.

2.- Weinstock D M, Brown A E. Rhodococcus equi: an emerging pathogen. Clin Infect Dis 2002; 34: 1379-85. doi: 10.1086/340259.

3.- Gundelly P, Suzuki Y, Ribes J A, Thornton A. Differences in Rhodococcus equi infections based on immune status and antibiotic susceptibility of clinical isolates in a case series of 12 patients and cases in the literature.
Biomed Res Int 2016; 2016: 2737295. doi: 10.1155/2016/2737295.

4.- Stewart A, Sowden D, Caffery M, Bint M, Broom J. Rhodococcus equi infection: A diverse spectrum of disease. IDCases 2019; 15: e00487 doi: 10.1016/j. idcr.2019.e00487.

5.- $\quad$ Torres-Tortosa M, Arrizabalaga J, Villanueva J L, Gálvez J, Leyes M, Valencia M E, et al. Prognosis and clinical evaluation of infection caused by Rhodococcus equi in HIV-infected patient: A multicenter study of 67 cases. Chest 2003; 123:1970-6. doi: 10.1378/ chest.123.6.1970.
6.- Corti M, Solari R, De Carolis L, Palmieri O, Rollet R, Shah H N. Infección por Rhodococcus equi en pacientes con SIDA. Análisis retrospectivo de 13 pacientes en Argentina. Rev Chilena Infectol 2014; 31: 4116. doi: 10.4067/S0716-10182014000400006.

7.- Drancourt M, Bonnet E, Gallais H, Peloux $\mathrm{Y}$, Raoult D. Rhodococcus equi infection in patients with AIDS. J Infect 1992; 24: 123-31.

8.- Rabagliati R, Morales A, Baudrand R, Jorquera J, Oddó D, García P, et al. Necrotizing pneumonia due to Rhodococcus equi in non HIV immunocompromised host. Case report and review. Rev Chilena Infectol 


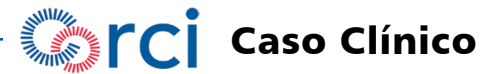

2005; 22: 155-60. doi: 10.4067/S071610182005000200006 .

9.- Topino S, Galati V, Grilli E, Petrosillo N. Rhodococcus equi infection in HIV-infected individuals: case reports and review of the literature. AIDS Patient Care STDS 2010; 24: 211-22. doi: 10.1089/apc.2009.0248.

10.- Enríquez Rodríguez A I, García Clemente M, Buchelli Ramírez H L. Severe pneumonia caused by Rhodococcus equi with hematogenous spread to the central nervous system in an immunocompromised patient. Arch Bronconeumol 2015; 51: 203-4. doi: 10.1016/j.arbres.2014.04.009.

11.- Pérez-Silvestre J, Abril López de Medrano V, Ortega González E. Infection due to Rhodococcus equi in HIV infected patients: four cases. Rev Clin Esp 2010; 210: 17-9. doi: 10.1016/j.rce.2009.03.001.

12. Giomi C V, Altamiranda C G, García J L,
Benchetrit A, Echazarreta S E, Corti M, et al. Disseminated Rhodococcus sp infection with central nervous system involvement in a patient with AIDS case report and literature review. Ann Infect Dis Epidemiol 2019; 4: 1039.

13.- Darraj M, Fainstein R, Kasper K, Keynan Y. Immune reconstitution syndrome secondary to Rhodococcus equi infection in a patient with HIV and Burkitt's lymphoma. J Infect Public Health 2017;10: 224-7. doi: 10.1016/j. jiph.2016.05.001.

14.- Vechi H T, Oliveira E T G, Freitas M R, Rossi F, Britto M H M F, Alves M D M. Chronic cavitary pneumonia by Rhodococcus equi in a highly prevalent tuberculosis country: a diagnosis challenge. Rev Inst Med Trop Sao Paulo 2018; 60: e74. doi: 10.1590/S16789946201860074.

15.- Le T, Cash-Goldwasser S, Tho P V, Lan N P, Campbell J I, van Doorn H R, et al. Diagnosing
Rhodococcus equi infections in a setting where tuberculosis is highly endemic: a double challenge. J Clin Microbiol 2015; 53: 1431-3. doi: 10.1128/JCM.02284-14.

16.- Ferretti F, Boschini A, Iabichino C, Gerevini S, De Nardi P, Guffanti M, et al. Disseminated Rhodococcus equi infection in HIV infection despite highly active antiretroviral therapy. BMC Infect Dis 2011; 11: 343. doi: 10.1186/1471-2334-11-343.

17.- Guyssens V, Vandekerckhove L, Colle I, De Rudder P, Blots S, Vogelaers D. Invasive infection with Rhodococcus equi-two case reports and review of literature. Acta Clin Belg 2010; 65: 271-5. doi: 10.1179/ acb.2010.058.

18.- Giguère S, Berghaus L J, Willingham-Lane J M. Antimicrobial resistance in Rhodococcus equi. Microbiol Spectr 2017; 5. doi: 10.1128/ microbiolspec.ARBA-0004-2016. 